\title{
Cuidados paliativos na atençáo domiciliar: a perspectiva de terapeutas ocupacionais ${ }^{1}$
}

\author{
Séfora Gomez Portela ${ }^{\mathrm{a}}$, Sandra Maria Galheigo ${ }^{\mathrm{b}}$ \\ ${ }^{a}$ Centro de Educação Especial Síndrome de Down (CEESD), Campinas, SP, Brasil

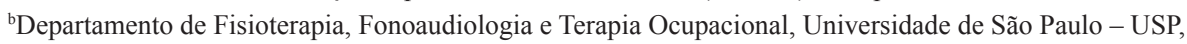 \\ São Paulo, SP, Brasil
}

\begin{abstract}
Resumo: A pesquisa objetivou conhecer e refletir sobre as perspectivas de terapeutas ocupacionais em relação à implementação dos cuidados paliativos na atenção domiciliar. Trata-se de estudo exploratório, qualitativo, através de entrevistas semiestruturadas, realizadas no segundo semestre de 2012 com oito terapeutas ocupacionais com experiência em cuidados paliativos no município de São Paulo. A análise de conteúdo identificou quatro temáticas: caracterização dos profissionais e trajetória no campo; compreensão do conceito de cuidados paliativos; atenção domiciliar e cuidados paliativos; e Terapia Ocupacional e cuidados paliativos na atenção domiciliar. Os resultados sugerem que a atuação do terapeuta ocupacional nesse campo tem ocorrido em diferentes níveis de atenção à saúde, sendo dirigida a pessoas com necessidades variadas. $\mathrm{O}$ uso do conceito dos cuidados paliativos pelas entrevistadas supera a noção de terminalidade, acompanhando as mudanças no perfil epidemiológico. Compreendem que a atuação profissional segue a tendência dos serviços nacionais de cuidados paliativos com concentração nos níveis especializados, mas manifestam a potência de sua implementação na atenção básica e domiciliar. Dentre os entraves para a prática foram apontados: complexidade do "estar no domicílio", peculiaridades dos cuidados paliativos com demandas de alto custo, falta de infraestrutura e a não implementação da política pública vigente. A formação profissional e a produção científica na área foram apontadas como insuficientes, embora identifiquem um movimento de mudança. As entrevistadas reconhecem os cuidados paliativos na atenção domiciliar como um campo potente de atuação profissional, mas que ainda requer estudo e discussão sobre seus limites e condições de oferecimento, especialmente no âmbito do SUS.
\end{abstract}

Palavras-chave: Terapia Ocupacional, Cuidados Paliativos, Assistência Domiciliar.

\section{Palliative care in home care: perceptions of occupational therapists}

\begin{abstract}
This research aimed at understanding and reflecting on the perceptions of occupational therapists regarding the implementation of palliative care in home care. This is an exploratory, qualitative study, through semi-structured interviews, conducted in the second semester of 2012 with eight occupational therapists with experience in palliative care in the city of São Paulo. Content analysis identified four themes: characterization and professional trajectory in the field, understanding the concepts of palliative care, home care and palliative care, and occupational therapy and palliative care in home care. The results suggest that the role of the occupational therapist in this field has taken place at different levels of health care, being addressed to people with varying needs. The use of the concept of palliative care by the interviewees exceeds the notion of end of life, following the changes in the epidemiological transition. They understand that professional services follow the trend of national palliative care services with focus on specialized levels, but manifest the importance of its implementation in primary and home care. Among the barriers to practice, they identified the complexity of "being at home ", peculiarities of palliative care with high cost demands, lack of infrastructure and implementation of the current policy. Professional training and scientific
\end{abstract}

Autor para correspondência: Sandra Maria Galheigo, Laboratório ACCALANTO, Centro de Docência e Pesquisa em Terapia Ocupacional, Faculdade de Medicina, Universidade de São Paulo, Rua Cipotânea, 51, Cidade Universitária, CEP 05508-900, São Paulo, SP, Brasil, e-mail: sandramg@usp.br

Recebido em Set. 30, 2013; Revisão em Mar. 1, 2014; Aceito em Mar. 7, 2014. 
production in the area were viewed as inadequate, although they identified a call for change. The interviewees recognized palliative care in home care as a strong professional field, but one still requiring study and discussions regarding its limits and conditions of implementation, especially in the Unified Health System.

Keywords: Occupational Therapy, Palliative Care, Home Nursing.

\section{Introdução}

É crescente a importância que se tem agregado à transformaçáo dos modos de organizar a atenção à saúde para consolidação do Sistema Único de Saúde (SUS), seja pela necessidade de aprimorar o cuidado por meio de açóes que produzam a integralidade da atenção, seja, também, pela necessidade de empregar modos mais eficazes na utilização dos recursos, dado que o modelo hegemônico, procedimento-centrado, tem implicado no aumento dos custos, derivado de vários aspectos, dentre os quais se destaca a incorporação tecnológica orientada pela lógica do mercado, incapaz de responder às necessidades de saúde da populaçáo (FEUERWERKER; MERHY, 2008).

A expansão dos serviços de atenção domiciliar observada em nosso país parece trilhar esse caminho, uma vez que é impulsionada por fatores semelhantes como: a transição demográfica, que evidencia o envelhecimento populacional; a mudança no perfil epidemiológico da população, com aumento das doenças crônicas, não transmissíveis; os custos crescentes do sistema hospitalar; o aumento da exigência de maior privacidade, individualização e humanização da assistência à saúde; e a necessidade de maior integração entre equipe, cliente/paciente e sua família (DUARTE; DIOGO, 2000). Segundo Fripp (2009), a atenção domiciliar tem se demonstrado potente enquanto modalidade substitutiva de cuidado, pois possibilita uma atenção mais próxima, individualizada e menos tecnicista se comparada à oferecida em ambiente hospitalar.

O emergente debate em torno das novas formas de organizar a atenção em saúde tem recuperado discussôes sobre o paradigma do cuidado, evidenciando a premência de que ele componha projetos de tratamentos integrais. É sobre essa perspectiva que se reafirma e se justifica a necessidade dos cuidados paliativos, uma vez que esses são reconhecidos como parte da assistência integral à saúde (MACIEL, 2006). Em crescente expansão no país, os cuidados paliativos também são identificados como um dos principais componentes motivacionais para o desenvolvimento da atenção domiciliar (FABRÍCIO et al., 2004).
O Ministério da Saúde, em sua portaria n. 2.527 , publicada em outubro de 2011, incorpora a necessidade de cuidados paliativos como um critério de inclusão nos serviços de atenção domiciliar, em suas modalidades 2 e 3 (BRASIL, 2011a). Em 16 de julho de 2012, tal portaria é alterada e redefinida através da publicaçáo da portaria n. 1.533, de modo que a partir dela, um número maior de municípios passa a preencher os pré-requisitos mínimos para implementação desses novos serviços (BRASIL, 2012a).

Sabe-se, entretanto, que a incorporação dos cuidados paliativos nas práticas de saúde é anterior a essas publicaçôes. Serviços foram criados no país a partir da década de 1980, com considerável expansão após a virada do século, derivados principalmente de programas voltados ao controle da dor. Os programas de cuidados paliativos vigentes têm sido implementados em hospitais gerais, hospitais de retaguarda e em programas de atendimento domiciliar.

Os cuidados paliativos foram definidos pela Organização Mundial de Saúde (OMS) em 1990, sendo seu conceito atualizado em 2002. Segundo a OMS, são

[...] um conjunto de medidas capazes de promover melhor qualidade de vida à pessoa com alguma doença que ameace a continuidade da vida, bem como a seus familiares, com suporte emocional, social e espiritual em equipe multiprofissional [...] (ORGANIZAÇÃO..., 2002 apud OTHERO; COSTA, 2007, p. 157).

O trabalho multiprofissional e interdisciplinar se faz fundamental nos cuidados paliativos. A partir de uma abordagem integrada, pautada em diversos conhecimentos teóricos e científicos, são construídas intervenções que contemplam aspectos físicos, psicossociais e espirituais, tanto do paciente como de familiares e cuidadores (DE CARLO; QUEIROZ; SANTOS, 2007).

As diretrizes estabelecidas pelo Ministério da Saúde (BRASIL, 2012b) em relação à Atenção Domiciliar reiteram essa noção, preconizando que o modelo de atençáo esteja organizado de forma multiprofissional e interdisciplinar. Propóe-se a criação de Equipes Multiprofissionais de Atenção 
Domiciliar (EMAD), supostamente compreendidas como equipes mínimas, compostas por médicos, enfermeiros, auxiliares/técnicos de enfermagem, fisioterapeutas e/ou assistentes sociais, e Equipes Multiprofissionais de Apoio (EMAP), com quadro de profissionais mais diversificado, devendo conter minimamente três dos seguintes profissionais: assistente social, farmacêutico, fisioterapeuta, fonoaudiólogo, nutricionista, odontólogo, psicólogo e terapeuta ocupacional.

O terapeuta ocupacional está habilitado para compor as equipes de atenção domiciliar pois embora não seja um dos profissionais pertencentes à equipe mínima, pode vir a integrar as equipes de apoio.

Considerando a recente menção aos cuidados paliativos na atenção domiciliar definida no âmbito do SUS e a inexistência de diretrizes referentes à atuação dos profissionais pelo Ministério da Saúde, o presente trabalho se propôs a conhecer e refletir sobre as perspectivas de terapeutas ocupacionais em relação à implementação dos cuidados paliativos na atenção domiciliar.

\section{Métodos}

A pesquisa foi organizada sob a forma de estudo exploratório, de caráter qualitativo, realizado por meio de entrevistas semiestruturadas (GIL, 1994; MINAYO, 2004). Foram entrevistados oito terapeutas ocupacionais com formação e experiências variadas no âmbito da assistência e ensino em cuidados paliativos e atenção domiciliar na cidade de Sáo Paulo (Tabela 1). Com o intuito de garantir um acúmulo de experiência profissional, o critério de inclusão da pesquisa previa conclusão da graduação em Terapia Ocupacional há no mínimo três anos, além da experiência em cuidados paliativos. Entretanto, durante a coleta de dados optou-se por acrescentar os profissionais em formação em serviço, modalidade de especialização que tem se expandido no país nos últimos anos, representando assim uma nova geração profissional que tenderia a enriquecer o conteúdo coletado. As participantes serão referidas neste artigo por E1, E2, etc.

As entrevistas foram norteadas por roteiro elaborado para o estudo, composto por sete perguntas que versaram sobre: a caracterização dos serviços nos quais estáo inseridas, a compreensão sobre os cuidados paliativos, a experiência profissional das entrevistadas em cuidados paliativos, a implementação dos cuidados paliativos na atenção domiciliar (perspectivas e necessidades), as contribuiçóes e limites da Terapia Ocupacional nesse contexto e a produção científica sobre o tema.

$\mathrm{O}$ desenho da pesquisa requereu sua organização em quatro fases: $1^{\text {a) }}$ Realização das entrevistas com oito profissionais; 2a) Transcrição das entrevistas; 3a) Análise de conteúdo e a elaboração das sínteses finais; 4a) Redação do artigo com os resultados finais da pesquisa.

Para realização da análise de conteúdo, as entrevistas foram gravadas e posteriormente transcritas. O material coletado foi organizado por temas, a partir de níveis de significação, possibilitando a identificaçáo de semelhanças, divergências, tendências entre o conteúdo expresso pelas profissionais.

\section{Resultados e discussão}

\subsection{Caracterização das entrevistadas e trajetória no campo dos cuidados paliativos}

Todos os sujeitos da pesquisa são do sexo feminino, formadas há, no mínimo, oito anos e, no máximo, há 24, exceto as duas aprimorandas, formadas nos dois últimos anos. Todas as participantes realizaram seu curso de graduaçáo no estado de Sáo Paulo, majoritariamente em universidades públicas (Tabela 1).

No que se refere à pós-graduação, a totalidade das profissionais possui formação ou está cursando, em suas distintas modalidades: aprimoramento, especialização, mestrado e doutorado. As áreas de concentração variam dentro dos campos de atuação da Terapia Ocupacional, não havendo predominância significativa; distribuem-se entre Geriatria e Gerontologia, Saúde Coletiva, Pediatria, Reabilitação Física e Cuidados Paliativos.

Embora todas identifiquem alguma atuação, ainda que esporádica, no campo dos cuidados paliativos, apenas uma das entrevistadas possui formação específica realizada no exterior. As demais buscavam aproximar-se do tema a partir da literatura, grupo de estudos, seminários, cursos de curta duração, congressos, workshops, estágios extracurriculares, dentre outros. A ainda baixa incidência de profissionais com formaçáo em Cuidados Paliativos denota a escassa oferta de cursos de pós-graduaçáo lato senso voltados a esse campo no Brasil. 


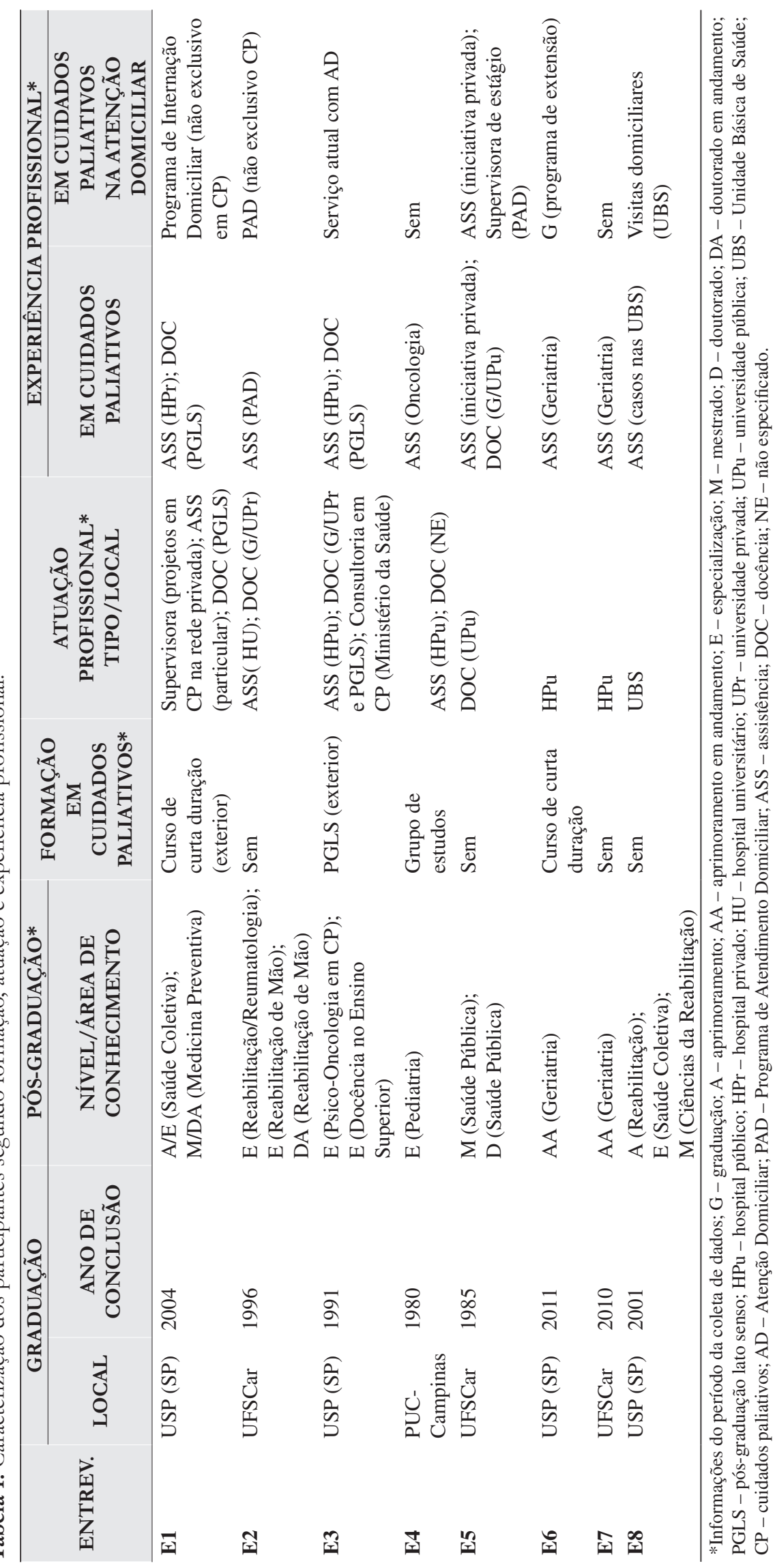


Sobre as áreas de atuação dessas profissionais, tem-se que estão distribuídas entre os três níveis de atenção à saúde, com predominância dos mais especializados. Trabalhavam, ou desenvolviam projetos em hospitais gerais e especializados ou em unidade básica de saúde há mais de seis anos, com exceção das aprimorandas. Havia quem realizasse também atividades de consultoria e atendimentos particulares. Cinco entrevistadas (E1, E2, E3, E4 e E5) estavam ligadas a atividades de ensino. Em sua maioria, referiram participação em equipe multiprofissional e vinculação ao Sistema Único de Saúde (SUS). Em relação à população atendida, notou-se uma propensão ao direcionamento a grupos populacionais específicos, principalmente idosos com algum grau de comprometimento, pacientes com quadros neurológicos ou câncer.

Dentre as participantes da pesquisa, apenas duas (E1 e E3) tinham sua prática mais centrada na questão dos cuidados paliativos: uma em hospital terciário, e outra, primordialmente, desenvolvendo atividades de consultoria e supervisão sobre o tema. Além disso, ambas ocupavam cargos de chefia, estavam ligadas a atividades de ensino e de produçáo científica em Cuidados Paliativos.

A experiência das profissionais entrevistadas em relação aos cuidados paliativos é também diversa. Apenas E1 e E6 se aproximaram do campo por interesse prévio, sendo as únicas a relatarem contato com o tema durante a graduação. Ambas formaram-se há menos de dez anos, dado importante para que se infira a atualidade do tema Cuidados Paliativos nos currículos da graduação.

A aproximação dos Cuidados Paliativos a partir da prática profissional constituia realidade expressiva entre os sujeitos da pesquisa e, conforme os relatos, acontecida nas últimas duas décadas,

naquela época, na década de 1990, en fazia uma reflexão sobre a finitude da vida humana, mais uma reflexão filosófica do que propriamente uma orientação para a prestação de cuidado a pessoas próximas a finitude (E5).

A incidência com que se deparavam com o tema também diferencia essas profissionais. Os serviços especializados concentram o maior número de casos, em detrimento dos serviços de menor complexidade tecnológica (unidades básicas de saúde e hospitais gerais): "Então eu trabalho na atenção básica desde 2004 e eu me lembro de ter acompanhado dois casos, mais sistematicamente, de cuidados paliativos"(E8). No entanto, como se verá no decorrer dos resultados apresentados, o baixo número de casos atendidos sob a perspectiva dos cuidados paliativos na atençáo básica não significa necessariamente que não há demanda para esse tipo de cuidado dentro dos serviços.

\subsection{Compreensão das entrevistadas sobre os cuidados paliativos}

Três entrevistadas (E1, E3 e E6) mencionaram a definição apresentada pela OMS, em 2002 (ORGANIZAÇÃO..., 2002 apud OTHERO; COSTA, 2007), quando questionadas sobre o que seriam os cuidados paliativos. As demais, ainda que não a tenham mencionado diretamente, definiram-no de modo equivalente, sendo a manutenção da qualidade de vida e a proposição de ações que garantam conforto os aspectos mais citados como elementos fundamentais desse tipo de atenção.

No que se refere à população alvo dos cuidados paliativos, notou-se, tanto na literatura como na manifestação das entrevistadas, uma concepção ampliada sobre quem poderia se beneficiar dessa modalidade de cuidado, sendo recorrente a menção da importância de seu início a partir do diagnóstico de uma doença náo responsiva ao tratamento curativo ou, ainda, concomitante ao tratamento ativo.

Apesar disso, notou-se que a implementação desse tipo de abordagem ainda não é efetiva, conforme exposto por uma das entrevistadas:
Só que na prática eu ainda acho difícil de ser implementado, especialmente numa realidade como o Brasil, então eu imagino, [...], que as equipes especificas de cuidado paliativo precisam estar vinculadas aos casos mais complexos, [...] de doenças mais avançadas, graves, para que a gente de fato consiga implementar isso nesse momento. Então, eu tendo a achar que a prática [...] acaba sendo voltada para quem está num momento mais avançado da doença, num momento mais grave, isso não necessariamente está relacionado ao tempo de vida, mas ao nivel de complexidade (E1).

Apenas uma entrevistada (E8) ainda associava os cuidados paliativos exclusivamente aos pacientes terminais, sugerindo tratar-se de um tipo de cuidado que é oferecido aos que se aproximam do fim da vida. Mas, em se tratando da terminalidade, há quem amplie o conceito para além dos cuidados finais propriamente ditos:

O cuidado paliativo é isso, ajudar a pessoa nesse processo de terminalidade, que não necessariamente é o cuidado final. Cuidado final 
para nós é a última semana, os últimos dias. $O$ último mês do paciente é cuidado final, mas todo paciente que sofre, tem sintomas sem controle, é elegivel para o cuidado paliativo (E3).

Um ponto conflitante dentro das perspectivas em análise se referiu ao paciente crônico. Embora E3 considerasse que esses pacientes poderiam ser beneficiados pelos programas de cuidados paliativos, admitia que não necessariamente a cronicidade implicava na limitação do período de vida, e, portanto, não poderiam ser considerados alvo desse tipo de cuidado. E1, E3, E4, E5 e E6, entretanto, ponderaram que a introdução dos cuidados paliativos está atrelada a nâo responsividade ao tratamento curativo, independente de serem casos crônicos ou não.

O reconhecimento da família como parte integral dos cuidados paliativos integrou o discurso de cinco entrevistadas (E1, E3, E6, E7 e E8), como se observa no excerto a seguir:

Cuidado paliativo a gente só faz quando atende paciente e família, então todo mundo que faz cuidado paliativo que não atende família na verdade não está fazendo cuidado paliativo, porque na definição da OMS é para o paciente e a familia (E3).

O período e local de formação das profissionais, conforme a análise, não tem relação com as definiçôes apresentadas, o que parece diferir é quando se considera a proximidade do profissional com o tema, de modo que aqueles com menor contato ou menor formação em Cuidados Paliativos tendem a limitar a atuaçâo profissional à importância do conforto e da qualidade de vida do paciente.

E1 e E3, identificadas como participantes com maior experiência prática em cuidados paliativos, demonstraram uma visão mais crítica sobre a distância entre o que seria ideal, preconizado pela OMS, e o que se tem feito de fato. Esse aspecto aponta que para a incorporação de profissionais de saúde a atendimentos domiciliares que ofereçam cuidados paliativos há que realizar-se um investimento em educação continuada, aspecto também referido pelas profissionais.

\subsection{Os cuidados paliativos na atenção domiciliar segundo as entrevistadas}

Duas participantes (E4 e E7) não possuíam experiência de atuação em cuidados paliativos na atenção domiciliar. Portanto, parte das perspectivas apresentadas está pautada na experiência e vivência da profissional nesse contexto e outra baseada no que se compreende como ideal para essa modalidade de cuidado.

A perspectiva das entrevistadas em relação à implementação dos cuidados paliativos na atenção domiciliar não seguiu uma tendência única, de modo que coexistiram posturas mais afirmativas, que reconheciam nas iniciativas como os Núcleos de Apoio às Equipes de Saúde da Família (NASF) açóes que trilham em direção a esse processo de consolidação do campo, com outras, mais hesitantes:

\section{Euvejoquetemmuitocampo, maseuachoqueainda falta muita estrutura para que isso aconteça (E2). Talvez nesse momento do nosso sistema de saúde, nem sempre a casa vai ser o momento onde a pessoa tem a melhor assistência possivel (E1).}

A principal tendência dentro dessa temática referiu-se ao entendimento das entrevistadas sobre a relevância dos cuidados paliativos na atenção domiciliar, a qual parece fundamentar-se nos limites encontrados em outras modalidades de atenção, principalmente no hospital, ambiente recorrente no cotidiano daqueles que têm uma doença que ameaça a continuidade da vida. Dentro da perspectiva dos cuidados paliativos, esse tipo de serviço é inadequado, pois potencializa a quebra da rotina e limita o contato com as pessoas queridas e significativas.

Atendo-se mais à questão da terminalidade, tem-se que "o hospital não é lugar de morrer, hospital é lugar de se curar da doença que se tem" (E3). Entretanto, reconhece-se também que nem sempre a casa do paciente constitui-se como espaço adequado de cuidado, o que pode determinar a continuidade do seguimento em estruturas hospitalares.

Verificou-se que, entre as entrevistadas atuantes em hospitais, o retorno ao domicílio, sempre que possível, constituia-se como um dos focos da intervenção:

a hora que você permite que o paciente volte para a casa dele, é a hora que você permite a reconstrução da identidade, ou o resgate mesmo de significados e sentidos (E3).

Como argumento favorável também foi mencionado o fator econômico, dado que a manutenção desses pacientes em enfermarias hospitalares implica em custos mais elevados, aspecto a ser considerado na assistência à saúde, uma 
vez que o crescente envelhecimento populacional no país propende ao aumento do número de usuários demandando cuidados paliativos.

Entretanto, destaca-se que os possíveis custos, que deixam de ser de responsabilidade do sistema de saúde, são repassados às famílias e, dada a desigualdade socioeconômica de nosso país, acarretam em condiçôes inapropriadas ao usuário. Iniciativas têm sido tomadas pelo governo federal nesse sentido, como a legislação que versa sobre a isenção ou redução das tarifas de energia elétrica de famílias de baixa renda que apresentem no domicílio dependentes de aparelhos que impliquem no consumo contínuo de energia, mas elas ainda são insuficientes (BRASIL, 2011b).

O relato das entrevistadas suscita o entendimento de que as açóes desenvolvidas em cuidados paliativos, no sentido mais técnico, pouco diferem estando o paciente no domićlio ou no hospital, estando as especificidades de cuidado mais atreladas à patologia e ao quadro clínico do paciente.

Apontam, entretanto, que a especificidade da entrada do profissional no domicílio é que exige mudanças na forma de conceber o cuidado, reconhecendo que

é muito complexo fazer assistência domiciliar, porque de fato você está entrando na casa do outro, e quando você está entrando na casa do outro, o espaço é do outro (E1).

Certa crítica é realizada nesse sentido, pois ainda de acordo com E1, é comum entre os profissionais a visão romântica da entrada no domicílio.

Constata-se que muito do que os participantes apresentam em relação à implementação dos cuidados paliativos na atenção domiciliar refere-se ao contexto do SUS, no qual mencionam a predominância de situaçóes socioeconômicas mais desfavorecidas. O cuidado no domicílio invariavelmente acarreta no aumento de gastos para a família, sendo esse um aspecto importante a ser considerado. Todavia, reconhece-se que situaçóes de maior vulnerabilidade não necessariamente inviabilizam essa modalidade de cuidado, pois conforme afirma a entrevistada E2,

a qualidade do tratamento está mais relacionada com as relaçōes interpessoais, interfamiliares $e$ com a equipe do que a condição financeira dela, ou se a atenção é privada ou pública.

Mas, ainda sobre esse aspecto, tem-se que frente à maior precariedade das famílias, a contrapartida oferecida pelos serviços de saúde deve ser também maior.
Os principais elementos apresentados como problemas frente à oferta dos cuidados paliativos na atenção domiciliar no âmbito do SUS referem-se à dificuldade encontrada para dispensação de medicamentos e equipamentos de auxílio, ambos de importância fundamental, por exemplo, no alívio de sintomas e controle da dor, açóes preconizadas nos cuidados paliativos. Somam-se a eles condiçóes de acessibilidade inapropriadas, considerando-se que esses usuários comumente residem em regiôes periféricas do município, e a falta de cuidadores, dado que muitas vezes os familiares não podem deixar o trabalho para assumir esse papel, pois dependem do salário para garantir, entre outras coisas, condiçóes mínimas de cuidado para o paciente. De acordo E3, a questáo dos cuidados paliativos ainda é muito incipiente no país frente às carências mais básicas, como saneamento e educação básica.

Todos os profissionais, exceto E3, referiram de diferentes formas que a ampliação das políticas públicas se faz necessária para consolidação dos cuidados paliativos na atenção domiciliar. Para E3, porém, as políticas já existem, restando apenas colocá-las em prática. Concebe ainda uma crítica em relação ao grande número de programas criados dentro da esfera governamental que náo chegam a ser implementados, muito possivelmente devido ao grande investimento financeiro demandado.

Outro aspecto mencionado como imprescindível para efetivação da atençáo domiciliar de modo geral, e não apenas referente aos cuidados paliativos, concerne à construção de uma rede entre os serviços de saúde capaz de garantir o mínimo suporte às famílias e aos pacientes que passam a ser cuidados no domicílio.

A prática das participantes confirma essa necessidade. A construção de estruturas mais sólidas dentro da rede de serviços, asseguraria, por exemplo, a emissão de atestados de óbito daqueles que venham a falecer no domicílio, minimizando os problemas de ordem burocrática comumente enfrentado pelos familiares em situaçóes como essa. Do mesmo modo, o estabelecimento de referência e contrarreferência mais efetivas entre os serviços facilitaria, entre outros aspectos, o processo de encaminhamento de casos com piora clínica.

Com intuito de suprir essa carência dentro do sistema de saúde, tem-se a mobilização de algumas das entrevistadas que atuam na atenção domiciliar, ou ainda daquelas que não atuam mas que reconhecem tratar-se de uma ação imprescindível dentro dos serviços nos quais estão inseridas. Assim, a seu modo, organizam-se junto 
às equipes, na tentativa de realizar visitas prévias a alta, objetivando não apenas conhecer melhor o ambiente para o qual o paciente será encaminhado como também na tentativa de articular-se com os serviços de saúde mais próximos ao domicílio, buscando assegurar rede mínima de apoio.

Embora apenas E4 tenha sugerido que o cuidado paliativo na atenção domiciliar não deva restringir-se ao espaço do domicílio, sendo necessário intervir em outros espaços que façam parte da rotina desse paciente e de sua família, tem-se, a partir da prática dessas profissionais, que essa é uma realidade compartilhada, pois ao buscar a articulação entre os serviços estão extrapolando a atuação circunscrita ao domicílio.

A particularidade da implementação dos cuidados paliativos na atençáo domiciliar dentro do município de Sáo Paulo, citada mais especificamente por E1, também foi elencada como problemática, pois, devido a sua grande extensão territorial, demanda maior investimento no desenvolvimento de estratégias específicas para garantia da qualidade da atenção prestada como, por exemplo, a organização regionalizada dos serviços.

Uma segunda tendência apontada trata da importância que agregam ao trabalho em equipe, reconhecendo como insuficiente a atuação individual do terapeuta ocupacional. Ressaltam a necessidade de formaçóes específicas para os profissionais da equipe, pressupondo as peculiaridades implicadas no trabalho em cuidados paliativos, como o enfrentamento constante de situações de terminalidade, morte e luto. Conforme indicado, a falta de formação usualmente interfere no trabalho realizado, pois muitos profissionais, por não estarem apropriados dos princípios propostos por essa modalidade de cuidado, intervêm de maneira não condizente.

A própria composição da equipe é apontada como um limite nesse contexto, pois além da questão técnica esbarra-se numa questão administrativa. Quanto maior a equipe, maiores são os gastos com a contratação e manutenção dos profissionais. Em circunstância de redução de custos, é comum a redução do quadro de recursos humanos.

Assim, a necessidade ou não da criação de equipes específicas de cuidados paliativos dentro da atenção domiciliar é controversa. Profissionais com maior aproximação hospitalar depreendem que os cuidados paliativos devam ser oferecidos por equipes especializadas nesse tipo de atenção. De outro lado, profissionais mais próximos da atenção básica ponderam que não necessariamente esse tipo de intervenção implique em profissionais com formação específica (paliativistas), pois o que tornaria uma ação paliativa seriam as discussóes que se fazem a respeito do caso.

Por fim, uma última tendência identificada refere-se à recorrente menção do papel da atenção básica na consolidação dessa modalidade de atenção, seja através da ação das equipes de saúde da família ou, de modo mais indireto, oferecendo suporte e continuidade às intervençôes realizadas no interior dos serviços mais especializados.

De outro lado, porém, discute-se a limitação da atenção básica nesse contexto, já que não se dispóe de uma série de recursos essenciais para condução desses casos como, por exemplo, medicações para o controle da dor. Assim, conforme relatado, apenas os casos menos complexos, que demandem ações pontuais e não impliquem em uma grande frequência de atendimentos conseguem ser acompanhados pela atenção básica. E, nesses, a intervenção mais comum é o oferecimento de suporte emocional e orientação às famílias.

\subsection{A terapia ocupacional e os cuidados paliativos na atenção domiciliar segundo as entrevistadas}

Nessa temática, o conteúdo expresso parece centrar-se na trajetória profissional de cada entrevistada que, conforme já apresentado, está distribuída entre os distintos campos da Terapia Ocupacional, sendo essa uma realidade também identificada pelos profissionais:

eu construi minha prática de acordo com a minha experiência e vejo que cada um faz um pouco isso. Então eu náo vejo uma receita, eu acho que as pessoas publicam muito da experiência delas, mas não que seja a única forma de realizar a atenção domiciliária ou os cuidados paliativos (E2).

Constata-se que a totalidade das entrevistadas vê nos cuidados paliativos desenvolvidos no âmbito domiciliar um campo possível de atuação, no qual a Terapia Ocupacional tem muito a contribuir.

É talhada para trabalhar dentro dessa lógica dos cuidados [referindo-se à perspectiva do cuidar em contraposição à do curar] e também, por extensão, dos cuidados paliativos, porque [...] é uma profissão que realmente vê, entende a saúde na sua complexidade. Entende e pode lidar 
realmente com vários determinantes de saúde, entendendo o contexto como um importante determinante da saúde (E5).

O terapeuta ocupacional é reconhecido como essencial nesse contexto, pois ao trabalhar com o desempenho ocupacional, desempenho funcional e com as atividades de vida diária, favorece o alcance de um dos principais desejos do paciente: a independência em seu próprio cuidado.

Entretanto, de acordo com as entrevistadas, os profissionais ainda parecem despertar para essa modalidade, sendo esse um movimento recente dentro da Terapia Ocupacional. Nesse sentido, a aprovação das especialidades, principalmente a que versa sobre Terapia Ocupacional em contextos hospitalares, é referida como algo que tende a intensificar a aproximação com o campo, como se constata na seguinte fala: "Eu acho que a hora que aprova uma especialidade, as pessoas começam a abrir os olhos, já na academia, e começam a vislumbrar, a visualizar esse campo" (E4).

Ainda que se apresente como recente essa inserção do terapeuta ocupacional, E4 e E5 acreditam que determinadas práticas desenvolvidas anteriormente à expansão dos cuidados paliativos no país, há mais de duas décadas, já se enquadravam nos pressupostos dessa modalidade de cuidado, apesar de não nomeadas como tal.

São diversas as açôes descritas pelas profissionais como contribuiçôes da Terapia Ocupacional nesse âmbito, com destaque para as adaptaçôes do ambiente e as intervençôes que visam o conforto, o bem-estar e a melhor qualidade de vida e a orientação aos familiares e cuidadores.

Constata-se que embora as entrevistadas lancem mão de diferentes estratégias, majoritariamente elas buscam propiciar ao sujeito intervençôes que favoreçam a continuidade das atividades significativas, com participação ativa em sua rotina, de modo a garantir algum tipo de autonomia, independência e satisfação, processo esse facilitado através da apropriaçáo que o profissional procura fazer por meio da história de vida do sujeito, reunindo elementos referentes à sua identidade $\mathrm{e}$ aos sentidos e significados atribuídos à vida.

São apresentadas também como contribuições da Terapia Ocupacional: a facilitaçáo do processo de despedida; a estimulação da circulação no domicílio, com intuito de possibilitar maiores trocas e interaçóes com o ambiente; orientaçóes sobre o posicionamento e transferência do paciente; estímulo à manutenção das habilidades/ capacidades; indicação de exercícios para prevenção de agravos; orientação da rotina no domicílio; técnicas de conservação de energia; entre outros. As orientaçóes relativas à fadiga são enfatizadas em cuidados paliativos com o objetivo de prevenir a hiperestimulação do paciente, principalmente durante o retorno ao domicilio. Alerta-se também sobre a necessidade de que seja considerada, além da acessibilidade, a segurança do paciente.

Referem que o terapeuta ocupacional, utilizando-se do recurso das atividades, tem grande apropriação para abordar questôes ligadas à despedida e à perda dos familiares de forma náo verbal, estratégia de intervenção importante junto aos pacientes que não querem falar sobre sua história e sobre a morte iminente. Ressalta-se ainda que o trabalho do profissional não se encerra com o óbito. Várias açóes são desenvolvidas junto às famílias enlutadas.

O trabalho em equipe, explicitado anteriormente como relevante, recebe aqui novas significaçóes. Embora as entrevistadas reconheçam a importância do diálogo, tem-se que ele, em determinadas circunstâncias, implica num processo árduo, que pode constituir-se como barreira na atuaçáo do terapeuta ocupacional.

A clareza do profissional em relação a seu papel e dos demais profissionais da equipe é apontada como essencial. Nem sempre cabe ao terapeuta ocupacional suprir a demanda apresentada pela equipe e/ou usuários. Muitas vezes a açáo do profissional se resume ao encaminhamento à outra especialidade, avaliada como mais adequada naquele momento.

Ao utilizar abordagens que valorizam a história de vida dos sujeitos, o terapeuta ocupacional possibilita o acontecimento de intervençóes mais contextualizadas à realidade deles, sendo essa uma contribuiçáo que se estende a toda a equipe. Outra contribuição seria o próprio trabalho com as equipes, em um papel de supervisão e matriciamento.

A segunda tendência observada refere-se à recorrente alusão às famílias ao se apresentar o aporte da Terapia Ocupacional, já que um número considerável de açóes desenvolvidas nesse âmbito é a elas dirigida. Tais açóes não se limitam às orientaçóes para o cuidado, mas abordam também questôes ligadas à organização dos papéis familiares diante da nova condição imposta pela doença, os sentimentos envolvidos frente à terminalidade e orientaçôes que pontuem para a família a importância de não restringir sua vivência à rotina do cuidado. 
Apesar da grande preocupação com os familiares presente no discurso dos profissionais, o que se constata é a reprodução de uma lógica que tende a delegar o papel de cuidador à família, como afirma E1:

\section{A assistência domiciliar pressupōe que a família tem que dar conta de cuidar, só que a gente sabe que a família não é exatamente isso, então a gente tem que tomar um pouco de cuidado nesse sentido.}

Atendo-se aos limites e barreiras identificados pelas entrevistadas nesse contexto, verifica-se que incluem: aspectos relativos à própria formação profissional, dificuldades ligadas ao trabalho em equipe, especificidades da atuação no campo e a atual configuraçáo do mercado de trabalho. Sobre essa última, assinalam a ainda limitada oferta de trabalho, com poucos serviços pautados nesse tipo de cuidado, aspecto que tende a somar-se à falta de reconhecimento do terapeuta ocupacional.

No que concerne ao reconhecimento do terapeuta ocupacional enquanto profissional apto a integrar essas equipes, identifica-se um ponto conflitante entre os sujeitos da pesquisa. Algumas falas sugerem que essa falta de reconhecimento do trabalho desenvolvido limita a atuação profissional, pois muitas ações deixam de ser validadas. Entretanto, há quem afirme o contrário, sendo a falta de reconhecimento resultante da baixa autoestima dos profissionais:

Porque a gente gosta de fazer um discurso de que ninguém entende a gente, [...] que ninguém sabe o que é TO. Eu acho que esse é um grande limitador para Terapia Ocupacional, porque enquanto a gente fica querendo que os outros aprendam o que a gente é, a gente esquece de mostrar para os outros o que a gente faz (E3).

Os problemas relativos à formação são elencados como limites na atuação do profissional em cuidados paliativos na atenção domiciliar. Distintos aspectos são identificados como falhas do processo formativo, sendo o primeiro deles atrelado à dificultosa construção do raciocínio clínico diante dos casos, implicando, muitas vezes, em açóes mecanizadas, proposição de atividades sem sentido, intervençóes descontínuas, entre outras lacunas que indicam a falta de clareza do profissional em relação a sua atuação. Acrescenta-se ainda o despreparo do terapeuta frente à frustração do não fazer do paciente.

A falta de conhecimento científico também foi mencionada, principalmente no que concerne à área médica (informaçôes relativas à patologia e ao uso de fármacos, por exemplo), uma vez que o identificam como significativo na comunicação com os demais profissionais da equipe. Essa apropriação é compreendida como influente no desempenho e validação da profissão nesse âmbito, conforme exposto:

Ficar com um discurso humanitário, filosófico, teórico mas não se apropriar dessa ciência médica que existe, dessa cultura hospitalar, a gente também não vai muito longe (E3).

A complexidade da atenção domiciliar é identificada como limite na atuaçáo, exigindo a entrada sensível do profissional, que deve estar atento às demandas daquele ambiente. A ampla visão do terapeuta ocupacional nesse processo traz implicaçôes diversas. Ao mesmo tempo em que se constitui como contribuição ao cuidado prestado, dado que comumente se atenta a detalhes náo observáveis por outros profissionais da equipe, pode tornar-se uma barreira, à medida que dificulta o estabelecimento de "prioridades" dentro desse contexto, assim como a identificaçáo de suas atribuiçóes enquanto terapeuta ocupacional.

A carência de recursos materiais e físicos, ainda que interfira na qualidade do atendimento prestado pela Terapia Ocupacional, não inviabiliza a atuação do profissional.

A questão da morte, recorrente nessa prática, e a ausência de debates relativos à terminalidade durante a graduaçáo foram mencionadas apenas por E8 como entraves na atuação do profissional, justificadas pela dificuldade de lidar com angústias pessoais diante das situações de terminalidade, e de abordar o tema junto ao paciente e sua famíli não só do terapeuta ocupacional mas de toda equipe.

Em relaçáo às perspectivas para o campo, a inclusão do terapeuta ocupacional na "equipe mínima” é apontada como algo imprescindível. Essa seria uma forma de garantir intervençôes mais contextualizadas no momento vivido pelo sujeito, pois possibilitaria o seu acompanhamento contínuo e a reavaliação frequente do trabalho realizado, uma vez que, ao se aproximar da terminalidade, o quadro clínico tende a apresentar rápidas oscilações, implicando em novas demandas e prioridades.

A entrada de mais profissionais no campo, com relativo aumento no número de publicaçóes sobre o tema, também desponta como uma perspectiva importante, pois conforme apresentado: "Falta a gente pesquisar, registrar, sedimentar, colocar isso de uma forma 'evidencial', para que não se fique só no 'achismo"'(E4). 


\subsection{Cuidados paliativos, atenção domiciliar e perspectivas para a Terapia Ocupacional: Iniciando o debate}

A compreensão que se tem dos cuidados paliativos tem assumido novas perspectivas ao longo de sua implementação. Cada vez mais se observa a ampliaçáo de seu conceito, antes centrado na questáo da terminalidade, como se constata na própria redefinição da OMS em 2002. (ORGANIZAÇÃO..., 2002 apud OTHERO; COSTA, 2007).

Assim, torna-se cabível que entre os profissionais entrevistados a compreensáo dos cuidados paliativos e a definiçấo dos pacientes que viriam a se beneficiar de tal cuidado apresente variaçóes, pois trata-se de um conceito ainda em construção, embora se saiba que esse entendimento está intrinsicamente relacionado à proximidade do profissional ao tema.

Segundo Menezes (2004), o modelo e implementação prática dos Cuidados Paliativos traz consigo um dilema: trata-se de um estágio da assistência, de uma nova forma de cuidar da fase avançada da doença ou, ainda, seria um projeto que propóe um novo modo de cuidar de qualquer doença e doente?

Somam-se a essas indagaçóes, as peculiaridades advindas das diferenças regionais, culturais e sociais da população atendida, que resultam em práticas ainda mais diversas. De acordo com Maciel (2008), a depender da realidade de cada país ou regiấo, a prática de cuidados paliativos deve ser adaptada, considerando-se os aspectos relevantes, como a disponibilidade de recursos materiais e humanos.

Assim, apesar do maior desenvolvimento dessa abordagem junto ao paciente com câncer, conforme apresentado por De Carlo, Queiroz e Santos (2007), atualmente a filosofia dos cuidados paliativos tem se direcionado a pacientes que apresentam doenças crônicas progressivas e incapacitantes, indicando uma possível adequação à mudança do perfil epidemiológico de alguns países, como o Brasil.

Desse modo, ao se referir à doença ativa, progressiva, ameaçadora à continuidade da vida, tem-se que os cuidados paliativos podem e devem ser indicados nos casos de doenças crônicas, em suas diferentes fases de evolução (MACIEL, 2008), não havendo sentindo, portanto, nas contradições relativas à sua inclusão.

Segundo Sakurada e Taquemori (2008), um programa adequado de cuidados paliativos inclui diversos níveis de atenção mas, conforme se constata a partir da inserção das entrevistadas, eles ainda concentram-se nos serviços mais especializados, embora, com base nas entrevistas, se confirme a viabilidade desse tipo de atenção nos diferentes níveis de complexidade, uma vez que as experiências de atuação relatadas se estendem da atenção básica aos hospitais terciários.

Atendo-se ao papel da atenção básica nesse processo, nota-se que é reconhecida como espaço potente para esse tipo de cuidado, sendo referida pelo Ministério da Saúde, nas diretrizes da portaria n. 2.527, publicada em outubro de 2011, como ordenadora do cuidado e da açáo territorial da atenção domiciliar, que inclui a atenção prestada a pacientes em cuidados paliativos (BRASIL, 2011a). Porém, como ressaltam Feuerwerker e Merhy (2008, p. 184):

[...] nem sempre a rede básica dispóe oportunamente de todos os materiais específicos requeridos em determinadas situaçôes de atenção domiciliar; e, sobretudo, de tempo [...],

referindo-se a sobrecarga de trabalho desses profissionais.

Para Maciel (2009), um bom programa de atendimento domiciliar tem como primeira necessidade a capacitação da equipe visitadora, vinculada à atenção primária. Acrescenta ainda que:

[...] É necessária a compreensão de gestores de saúde no sentido de prover uma equipe exclusiva para os Cuidados Paliativos no domicílio, o que muito facilita o trabalho e possibilita de fato a boa paliação no nível da atenção primária. Há que se garantir uma política de medicamentos, que devem ser dispensados de forma regular, com controle pela equipe local. As equipes necessitam de um núcleo ou base e de um sistema de comunicação 24 horas/dia e sete dias por semana, para o atendimento imediato de situaçóes de emergência. Nessas situaçóes deve ser garantido o transporte do doente para o hospital de referência em Cuidados Paliativos. (MACIEL, 2009, p. 82).

Pressupondo essas condiçôes como ideais, tem-se, conforme o relato das profissionais, uma realidade ainda distante dos serviços da rede de atenção básica do país.

Prosseguindo com os pré-requisitos para implementação da atenção domiciliar, e consequentemente dos cuidados paliativos nesse âmbito, Feuerwerker e Merhy (2008) assinalam a 
necessidade do apoio ativo de um cuidador que se responsabilize pelo acompanhamento do usuário sob cuidado. Ainda segundo esses autores,

Essa modalidade implica, portanto, em transferir responsabilidades, ou seja: uma parte do cuidado que institucionalmente seria realizado pela equipe de saúde passa a ser realizada pelo cuidador ou pela família. Com isso, as famílias ganham a possibilidade de "disputar" o projeto terapêutico que será instituído em cada situação (FEUERWERKER; MERHY, 2008, p. 185).

Verifica-se, tanto na literatura como no discurso das entrevistadas, a associação espontânea entre o papel de cuidador e a responsabilidade do familiar. São poucos ainda os profissionais que assumem uma postura crítica frente a essa realidade e redimensionam a participação do familiar no cuidado, que nem sempre ocupará esse papel. Muito frequente na atenção domiciliar - o pressuposto da família como cuidadora - intensificam-se os cuidados paliativos, possivelmente pela existência de situaçôes clínicas ainda mais complexas, implicando em maior grau de dependência.

A complexidade dessa modalidade de atenção é decorrente de um amplo conjunto de variáveis. De acordo com Othero (2012, p. 197):

A atenção domiciliar tem especificidades, e o contexto sociocultural do paciente deve ser considerado para a efetividade das intervençôes propostas. As vantagens relacionadas ao tratamento e a observação in loco [...] podem também funcionar como fatores que complexificam a assistência prestada.

Apesar de mencionada durante as entrevistas, até o momento são poucos os profissionais que reconhecem tal complexidade, o que pode acarretar intervençóes violentas e iatrogênicas, através de proposiçóes que desconsiderem os valores contidos naquele ambiente e naquela família. Para Othero (2012, p. 199),

[...] o lar de uma pessoa é recheado de histórias, marcas e afetos, e mudanças aparentemente simples podem ter um grande impacto na vida dos sujeitos que ali residem.

Ainda segundo Feuerwerker e Merhy (2008), as famílias trazem consigo diferentes desafios, cabendo ao profissional descobrir a melhor maneira de enfrentar as singularidades.
Soma-se à complexidade da atenção domiciliar, tratando-se de cuidados paliativos, as questóes relativas à morte. Segundo Silva e Kovacs (2007), a abordagem dos cuidados paliativos no domicílio possibilita maior aproximação do paciente com sua própria identidade. Nesse contexto, é fundamental que a intervenção se dê de modo interdisciplinar e multiprofissional, pois possibilita o diagnóstico da realidade em que o paciente está inserido sob diversas perspectivas, visando o estabelecimento da saúde como um todo. Para as autoras, morrer no domicílio deve ser uma opçáo discutida com todos os envolvidos e constantemente reavaliada, sendo o auxílio profissional nesses casos de grande importância.

Poucos terapeutas ocupacionais tratam pessoas em processo de morte. Aprender esse papel e essa funçáo parte da premissa de que a pessoa precisa tomar contato com os seus próprios sentimentos sobre a morte e sobre o morrer antes de trabalhar efetivamente com o paciente terminal [...] (SILVA; KOVACS, 2007, p. 318).

Apesar de mencionado, o aspecto da dificuldade em lidar com a morte aparece muito mais atrelado a uma crítica à formação e menos a um limite do profissional:

A educação dos profissionais de saúde ainda presta pouca atençáo às questóes da morte e do morrer. Isso resulta em profissionais qualificados com restrito entendimento das necessidades da pessoa em estado terminal e de sua família. Essa educação precisa enfatizar o treinamento em cuidados domiciliares na comunidade, levando-se em conta que nos países em desenvolvimento é no domicílio que a maioria das pessoas é cuidada (SILVA; KOVACS, 2007, p. 313).

Essa, porém, não é uma carência exclusiva dos cursos de Terapia Ocupacional. Segundo Kira, Montagnini e Barbosa (2008), ainda é restrito o número de escolas que oferecem elementos curriculares em cuidados paliativos e são poucos os serviços que oferecem treinamento especializado na área, de modo que a maioria dos profissionais que busca especialização é autodidata ou a realiza fora do país, situação também descrita pelas entrevistadas.

Em contraposição a essa crítica, há que se considerar a atual tendência dentro dos cursos de graduação na área de saúde de priorização da formação de profissionais generalistas. Possivelmente, os conteúdos relativos aos cuidados 
paliativos são dimensionados à especialidade, cabendo ao profissional recorrer a cursos de pós-graduação, o que não quer dizer, entretanto, que conteúdos básicos relativos ao tema não possam ser introduzidos ainda na graduação.

Para além da questão dos aspectos relativos à abordagem do tema da morte, cita-se a insuficiente formação para construção do raciocínio clínico frente aos casos e a falta de conhecimento científico. Sobre esse último, Maciel (2008, p. 24) afirma que

[...] os cuidados paliativos precisam ser rigorosamente administrados no âmbito das práticas de saúde, com intenso controle e aplicação de fundamento científico à sua prática, para jamais serem confundidos com descaso, desatenção, ausência de assistência ou negligência.

De acordo com Feuerwerker e Merhy (2008), a depender da configuração do "objeto" do trabalho da atenção domiciliar, diferentes modalidades de organização do cuidado são estabelecidas, com variação do tipo de tecnologia de cuidado em saúde empregado e, também, com distintas implicaçóes para os profissionais.

Conforme caracterização dos sujeitos da pesquisa constata-se que estão inseridos em serviços com distintos "objetos de trabalho" e que, muitas vezes, construíram sua prática nesse contexto, a partir da experiência profissional prévia, que comumente não envolvia a atuação em cuidados paliativos, sendo a aproximaçáo com o tema relativamente recente se comparada a outras áreas de atuação da profissão.

Entretanto, como aponta Othero (2012, p. 201):

[...] é imprescindível reforçar e ressaltar que a assistência extra-hospitalar é espaço de atuaçáo do terapeuta ocupacional, e - cada vez mais - a categoria terá de se organizar para ocupar tal lugar [...],

o que pode ser estendido à atuação em cuidados paliativos, também pertencente à especialidade dos contextos hospitalares. A importância dessa fundamentação científica é reconhecida pela Terapia Ocupacional e, de acordo com Ferrer e Santos (2007), os registros dos achados científicos e dos resultados do trabalho na área da assistência terapêutica são fundamentais para a consolidação desse campo da atuação.

Entretanto, em revisão da literatura nacional em cuidados paliativos, constata-se que poucas incluem o terapeuta ocupacional como profissional integrante da equipe. A escassez de produção científica é observada também dentro da própria Terapia Ocupacional. Em levantamento bibliográfico junto às bases de dados Biblioteca Virtual de Saúde e Scielo, em fevereiro de 2014, utilizando como descritores "terapia ocupacional" e "cuidados paliativos", apenas três artigos foram identificados (OTHERO, 2012; QUEIROZ, 2012; GARCIA-SCHINZARI; SPOSITO; PFEIFER, 2013). Os demais materiais produzidos por terapeutas ocupacionais brasileiros compóem-se em geral de artigos publicados em revistas não indexadas em bases de dados (DE CARLO et al., 2005; OTHERO; COSTA, 2007) e em capítulos de livros (DE CARLO; QUEIROZ, 2007; OTHERO, 2009). O levantamento da literatura internacional da Terapia Ocupacional em cuidados paliativos apresenta volume maior de publicaçóes. Pesquisa utilizando os mesmos descritores na base de dados Scopus, em fevereiro de 2014, resultou em 96 produtos, sendo 69 artigos e 27 revisões de literatura, que não foram analisados já que o foco desta pesquisa era estudar a realidade brasileira da área.

Segundo as entrevistadas, a reduzida produção científica deve-se a diversos fatores, dentre os quais a indisponibilidade de tempo do profissional frente à demanda de trabalho.

Outro aspecto mencionado como possível contribuinte para escassez de publicação refere-se à entrada recente dos terapeutas ocupacionais no campo, aspecto esse também atrelado a outras implicaçôes referentes à consolidação da Terapia Ocupacional em contextos hospitalares.

Todavia, essa parece ser uma realidade em transição. $\mathrm{O}$ número de terapeutas ocupacionais dedicados aos cuidados paliativos e inseridos em programas domiciliares com tal foco tem se expandido de maneira que sua importância tem sido afirmada como:

Possibilidade de construçáo de brechas de vida, potência, criação e singularidade, em um cotidiano por vezes empobrecido e limitado pela doença. A vida não pode perder seus sentido e significado até o último momento, e deve-se promover, de fato, a dignidade ao paciente fora da possibilidade de cura [...] assim, a intervenção em Terapia Ocupacional é fundamental, pois ainda que o cotidiano esteja muito limitado, sem a possibilidade de escolhas e/ou fazeres, a vida não pode perder seu sentido. Em toda sua atuação, o terapeuta ocupacional busca criar possibilidades de ampliação da autonomia e das possibilidades do fazer, compreendendo as atividades como possibilitadoras de experiência de 
potência, permitindo o resgate de capacidades remanescentes, bem como a criação de projetos a serem realizados. Toda a intervenção está voltada para a permanência de atividades significativas no cotidiano do paciente e de sua família (OTHERO, 2009, p. 238).

Cabe ressaltar como ação prioritária na consolidação do terapeuta ocupacional enquanto profissional apto a atuar em cuidados paliativos na atenção domiciliar a maior apropriação das discussóes realizadas no âmbito do Ministério da Saúde, pois conforme identificado nas entrevistas, apenas uma das profissionais conhecia as portarias citadas.

Apesar do pouco contato das entrevistadas com as publicaçóes ministeriais, muito do que foi apresentado como perspectiva para implementação dos cuidados paliativos na atenção domiciliar está previsto nas portarias publicadas, especificamente através da criação do programa do governo federal denominado Melhor em Casa, lançado em novembro de 2011 (BRASIL, 2012b).

A perspectiva do terapeuta ocupacional quanto à implementação dos cuidados paliativos na atenção domiciliar ruma ao reconhecimento do campo enquanto área de trabalho. Identifica-se um discurso fundamentado nas contribuiçóes que esse profissional tem a oferecer, com apontamentos condizentes aos achados da literatura sobre os meios necessários para sua implementação.

Como aponta Menezes (2004, p. 212),

[...] não há dúvidas de que os Cuidados Paliativos, divulgados como uma alternativa aos excessos de uma medicina tecnológica, propóem uma mudança na relação de poder entre equipe/paciente."

Em consonância, Feuerwerker e Merhy (2008, p. 186) apresentam que:

A casa, como espaço de cuidado, pode remeter a uma identificação e proximidade do cuidador para além da função técnica e da instituição hospitalar. Esses novos ingredientes, associados à maior autonomia das famílias na produção do projeto terapêutico, podem possibilitar às equipes operar na lógica da desinstitucionalização, potencializando novos lugares do cuidado, novas práticas, novas invençóes no agir em saúde, novas maneiras de produzir sentidos para a vida/morte.

Nessa perspectiva, avalia-se que o terapeuta ocupacional, pautando-se em seus saberes, lançando mão de recursos e técnicas apropriados às necessidades dos sujeitos, tem competência necessária para compor esse novo agir em saúde.

\section{Considerações finais}

Considera-se que o conteúdo apresentado pelas participantes durante as entrevistas representa o início de um importante conjunto de reflexóes acerca da implementação dessa modalidade de cuidado.

Salvo algumas peculiaridades da pesquisa, que restringiu-se a profissionais atuantes no município de São Paulo, o qual apresenta uma realidade bastante diversa de outras regiôes do país, composto em sua maioria por municípios de pequeno porte, com menos de 20 mil habitantes, tem-se que as perspectivas apresentadas em relação ao campo podem contribuir para ampliação das discussóes que se têm relativas ao tema. Estudos territoriais e de caso poderiam dar continuidade a esta pesquisa, no sentido de explorar as singularidades dos cuidados paliativos realizados por terapeutas ocupacionais no atendimento domiciliar.

Para maior inserção do terapeuta ocupacional nesse contexto de cuidado, avalia-se a primazia do fomento ao campo dentro dos espaços de ensino, assim como a realização de mais estudos sobre o tema.

Em relação aos profissionais já atuantes em cuidados paliativos na atenção domiciliar, ressalta-se a importância do registro sistemático das açóes desenvolvidas, favorecendo posteriores publicaçóes, assim como maior apropriação das discussóes realizadas a nível federal, seja no âmbito ministerial, ou ainda dentro das próprias associaçóes profissionais, com intuito de potencializar a consolidação do campo e garantir a sua expressividade dentro da Terapia Ocupacional.

\section{Referências}

BRASIL. Ministério da Saúde. Portaria no 1.533 , de 16 de julho de 2012. Altera e acresce dispositivos à Portaria no 2.527/GM/MS, de 27 de outubro de 2011, que redefine a Atenção Domiciliar no âmbito do Sistema Único de Saúde (SUS). Diário Oficial da República Federativa do Brasil, Poder Executivo, Brasília, DF, 16 jul. 2012a.

BRASIL. Ministério da Saúde. Secretaria de Atenção à Saúde. Melhor em casa - a segurança do hospital no conforto da sua casa. Brasília, DF: Ministério da Saúde, 2012b. (Caderno de Atenção Domiciliar, v. 1).

BRASIL. Ministério da Saúde. Portaria no 2.527, de 27 de outubro de 2011. Diário Oficial da República Federativa do Brasil, Poder Executivo, Brasília, DF, 27 out. 2011a.

BRASIL. Ministério de Minas e Energia e da Saúde. Portaria Interministerial $n^{\circ}$ 630, de 8 de novembro de 
2011. Diário Oficial da República Federativa do Brasil, Poder Executivo, Brasília, DF, 09 nov. 2011b.

DE CARLO, M. M. R. P.; QUEIROZ, M. E. G. Dor e cuidados paliativos: Terapia Ocupacional e interdisciplinaridade. São Paulo: Roca, 2007.

DE CARLO, M. M. R. P.; QUEIROZ, M. E. G.; SANTOS, W. A. Terapia ocupacional em dor e cuidados paliativos: princípios, modelos de intervenção e perspectivas. In: DE CARLO, M. M. R. P.; QUEIROZ, M. E. G. Dor e cuidados paliativos: terapia ocupacional e interdisciplinaridade. São Paulo: Roca, 2007. p. 126-145.

DE CARLO, M. M. R. P. et al. Terapia Ocupacional em dor e cuidados paliativos: constituiçáo do campo e formação profissional. Revista Dor, São Paulo, v. 6, n. 2, p. 560-566, 2005.

DUARTE, Y. A. O; DIOGO, M. J. D. Atendimento domiciliar: um enfoque gerontológico. Atheneu: São Paulo, 2000.

FABRÍCIO, S. C. C. et al. Assistência domiciliar: A experiência de um hospital privado do interior paulista. Revista Latino-Americana de Enfermagem, Ribeirão Preto, v. 12, n. 5, p. 721-726, 2004.

FERRER, A. L.; SANTOS, W. A. Terapia ocupacional na atenção a pacientes com dor oncológica e em cuidados paliativos. In: DE CARLO, M. M. R. P.; QUEIROZ, M. E. G. Dor e cuidados paliativos: Terapia Ocupacional e interdisciplinaridade. São Paulo: Roca, 2007. p. 146-166. FEUERWERKER; L. C. M.; MERHY, E. E. A contribuição da atenção domiciliar para a configuração de redes substitutivas de saúde: desinstitucionalização e transformação de práticas. Revista Panamericana de Salud Pública, Washington, v. 24, n. 3, p. 180-188, 2008. http://dx.doi.org/10.1590/S1020-49892008000900004 FRIPP, J. Ação prática do profissional de cuidados paliativos no domicílio. In: ACADEMIA NACIONAL DE CUIDADOS PALIATIVOS. Manual de cuidados paliativos. Rio de Janeiro: Diagraphic, 2009. p. 245-257. GARCIA-SCHINZARI, N. R.; SPOSITO, A. M. P.; PFEIFER, L. I. Cuidados paliativos junto a crianças e adolescentes hospitalizados com câncer: o papel da terapia ocupacional. Revista Brasileira de Cancerologia, Rio de Janeiro, v. 59, n. 2, p. 239-247, 2013.

GIL, A. C. Métodos e técnicas de pesquisa social. 4. ed. São Paulo: Atlas, 1994.

KIRA, C. M.; MONTAGNINI, M.; BARBOSA, S. M. M. Educação em cuidados paliativos. In: CREMESP.
Cuidado Paliativo. São Paulo: CREMESP, 2008. p. 595-612.

MACIEL, M. G. S. A terminalidade da vida e os cuidados paliativos no Brasil: consideraçóes e perspectivas. Revista Prática Hospitalar, São Paulo, v. 47, n. 8, p. 46-49, 2006.

MACIEL, M. G. S. Definições e princípios. In: CONSELHO REGIONAL DE MEDICINA DO ESTADO DE SÃO PAULO - CREMESP. Cuidado paliativo. São Paulo: CREMESP, 2008. p. 15-32. (Cadernos CREMESP).

MACIEL, M. G. S. Organização de serviços de cuidados paliativos. In: ACADEMIA NACIONAL DE CUIDADOS PALIATIVOS -ANCP. Manual de cuidados paliativos. Rio de Janeiro: Diagraphic, 2009. p. 72-85.

MINAYO, M. C. S. O desafio do conhecimento: pesquisa qualitativa em saúde. 8. ed. São Paulo: Hucitec, 2004.

MENEZES, R. A. Em busca de uma boa morte: antropologia dos cuidados paliativos. Rio de Janeiro: Fiocruz, 2004.

OTHERO, M. B. Papel do Terapeuta Ocupacional na equipe de Cuidados Paliativos. In: ACADEMIA NACIONAL DE CUIDADOS PALIATIVOS - ANCP. Manual de cuidados paliativos. Rio de Janeiro: Diagraphic, 2009. p. 237-238.

OTHERO, M. B.; COSTA, D. G. Propostas desenvolvidas em cuidados paliativos em um hospital amparador: Terapia Ocupacional e psicologia. Revista Prática Hospitalar, São Paulo, v. 52, n. 9, p. 157-160, 2007.

OTHERO, M. B. Terapia ocupacional na atenção extra-hospitalar oferecida pelo hospital. Cadernos de Terapia Ocupacional da UFSCar, São Carlos, v. 20, n. 2, p. 195-202, 2012

QUEIROZ, M. E. G. Atençáo em Cuidados Paliativos. Cadernos de Terapia Ocupacional da UFSCar, São Carlos, v. 20, n. 2, p. 203-205, 2012.

SILVA, S. N. P.; KOVACS, A. C. T. B. Terapia ocupacional na atenção domiciliar a paciente com dor e em cuidados paliativos. In: DE CARLO, M. M. R. P.; QUEIROZ, M. E. G. Dor e Cuidados Paliativos: Terapia Ocupacional e interdisciplinaridade. São Paulo: Roca, 2007. p. 307-325.

SAKURADA, C. K.; TAQUEMORI, L. Y. Assistência domiciliar. In: CONSELHO REGIONAL DE MEDICINA DO ESTADO DE SÃO PAULO - CREMESP. Cuidado Paliativo. São Paulo: CREMESP, 2008. p. 120-127. (Cadernos CREMESP).

\section{Contribuição dos Autores}

Ambos os autores foram responsáveis pela concepção da pesquisa e revisão final do artigo. Séfora Portela responsabilizou-se pela coleta e análise de dados e redação dos resultados. Sandra Galheigo orientou a pesquisa.

\section{Notas}

${ }^{1}$ Artigo produto de trabalho de conclusão de curso apresentado ao Curso de Terapia Ocupacional da Faculdade de Medicina da Universidade de São Paulo, com aprovação do Comitê de Ética em Pesquisa desta Faculdade sob protocolo de pesquisa no 234/12 em 08/08/2012. 